\title{
Experiences with A Freshman Engineering Problem Solving and Reasoning Course
}

\author{
S. Cem Karacal, John A. Barker, Jacob Van Roekel \\ Mech.\& Ind. Eng./ Philosophical Studies/ Mech. \& Ind. Eng. \\ skaraca@siue.edu/jbarker@siue.edu/jvanroe@siue.edu \\ Southern Illinois University, Edwardsville, IL 62026
}

\begin{abstract}
This paper describes our experiences with a new freshman-level engineering problem solving course jointly designed by the School of Engineering and the Department of Philosophical Studies. The main objective of the course is to incorporate critical thinking skills into the scientific problem solving method. It has the additional objective of enhancing skills in communication, teamwork, technical writing, and personal development. Experimental offerings of the course have produced encouraging results. In this paper we will report on our experiences with the course, which has now become an established course in the engineering curriculum.

\section{INTRODUCTION}

The School of Engineering at Southern Illinois University at Edwardsville (SIUE) has been experiencing retention problems similar to other engineering schools in the nation. The engineering students typically have no contact with engineering faculty and subject matter until their junior year. Preliminary studies on SIUE engineering students indicated that most of the retention problems are encountered during the basic science and general education courses. The main reasons for this appear to be the dearth of faculty-student contact during the students' first two years, and the lack of exposure to basic engineering concepts and problem solving methods. As a result, the students fail to see the link between the basic courses and engineering, and are not highly motivated to overcome the hardships of the first two years. This course is designed to create a lasting interest in engineering and to enhance essential skills and personal development.

The course is offered to first year engineering students on an optional basis. The students in the course are given the opportunity to take a critical thinking proficiency exam administered by the Philosophical Studies Department. If they pass, they receive academic credit for the department's Critical Thinking course, which satisfies one of the general education course requirements.
\end{abstract}

In this paper we will report on our findings with the first two experimental offerings of the course, which have produced encouraging results in terms of student achievements and student assessments of the course. The paper will also provide information on course content and format, along with an analysis of student evaluations of the course. 


\section{CRITICAL THINKING CONTENT}

The course design is based on the premise that logic and reasoning principles are the foundations of sound problem solving skills. When first encountering the type of reasoning problems covered in this course, many of the students assume that special innate skills are required. They eventually come to realize that once the basic rules of logic are understood, significant improvements in reasoning skills can be achieved through training and practice.

In the first half of the semester students learn the fundamental techniques of argument analysis and evaluation. Through lectures, discussions, and the use of a special software program, ProtoThinker, the students acquire an understanding of the principles of categorical logic and propositional logic, and develop skill in assessing arguments and inferences. This provides the students with direct preparation for the proficiency exam. The class meetings focus on explanations of reasoning principles and on practice sessions applying the principles. Basic techniques such as Venn diagrams, truth tables, formal proofs, and identification of premises and conclusions of arguments are discussed and applied to numerous examples.

\section{ProtoThinker Software}

ProtoThinker $^{1}$ : A Model of the Mind is an application developed by Professor Barker and published by Wadsworth Publishing Company. The core of this Prolog-based program is a computational model of the mind that enables users to converse in natural language with a simulated cognitive agent. The agent's mental operations, which are fully observable, model such cognitive processes as language understanding, formation of thoughts and memories, deductive and inductive reasoning, and rational decision making. The program has several modules designed for enhancement and assessment of reasoning skills. The students have access to ProtoThinker in campus computer labs, and the software is also made available to those who want to use it on their own personal computers. The students are strongly encouraged to use ProtoThinker to improve their reasoning skills and prepare for the proficiency exam.

The GameMaster Module contains logic games that provide students with guidance and practice in evaluating arguments in an interactive manner. An endless supply of computer generated problems prevents reliance on memorization and encourages mastery of logical principles. Of the four levels of difficulty, the first two provide assistance and training during the argument evaluation process. The students receive instruction in the principles for analyzing and assessing arguments, and obtain immediate feedback on their responses, including explanations of why the responses are correct or incorrect. The last two levels provide feedback on responses but no assistance during the problem-solving process.

The QuizMaster Module enables students to assess their progress by constructing tests that can be taken on screen and scored by computer, or printed and taken in a conventional manner. The multiple-choice tests can be of any length and can contain any combination of categorical or propositional logic problems created and randomized by the software. When taken on screen, the tests are immediately evaluated and the score is displayed to the student. 
Professor Barker is a guest speaker in several of the class meetings during the logic and reasoning discussions, and provides instruction on how to analyze and evaluate arguments. Arguments are evaluated with respect to both validity and soundness -- an argument is valid provided that the premises, if true, are capable of making the conclusion acceptable, and an argument is sound provided that it is valid and the premises are in fact true. The class time is used to work problems and interact with ProtoThinker. The following examples illustrate the types of arguments students are expected to evaluate successfully.

\section{Categorical Reasoning:}

Categorical logic deals with inferences involving classes of objects. Example:

ARGUMENT: Anyone who is an experienced engineer is a reliable employee, and at least one person who is working on the software project is an experienced engineer. Therefore, at least one person who is a reliable employee is working on the software project.

FACTS: No one who is a reliable employee is working on the software project. Everyone who is a reliable employee is an experienced engineer.

EVALUATION: The argument is:
(A) Valid but not sound
(B) Valid but possibly unsound
(C) Both invalid and unsound
(D) Sound

\section{Propositional Reasoning:}

Propositional logic deals with inferences involving relationships between situations and events expressed by such connectives as "if," "only if," “or," and "unless." Example:

ARGUMENT: The alarm is activated if the system checks evaluate to not-false, and the manualmonitor system is not operational if the system checks evaluate to true; hence, the alarm is activated if the manual-monitor system is not operational.

FACTS: The system checks evaluate to not-false if the manual-monitor system is not operational. The alarm is activated if the system checks evaluate to not-false.

EVALUATION: The argument is:

(A) Neither valid nor sound

(B) Unsound despite being valid

(C) Valid but possibly unsound

(D) Both valid and sound

Working with such examples, the students learn to analyze arguments by attending to structureindicators and identifying premises and conclusions. After discerning the argument's essential components, the students apply inference rules to determine validity and soundness. (To enhance motivation, the ProtoThinker software allows the content of the arguments to be tailored to the specific domain of engineering.) The students' performance improves steadily with practice, and judging from their proficiency exam scores, most of the students eventually succeed in attaining high levels of competence. 


\section{THE PROFICIENCY EXAM}

The two-part proficiency exam consists of a ProtoThinker-generated test called the Argument Evaluation Test and a standardized test called the California Critical Thinking Skills Test ${ }^{2}$. The Argument Evaluation Test contains 20 problems resembling those illustrated above. Students taking PHIL 106, the critical thinking course offered by the Philosophical Studies Department, average 5 correct responses on pretests and 10 on posttests. The California test contains 34 problems similar to those found in the analytical and logical reasoning sections of the GRE exam. The national average for college seniors on the California test is 15 correct responses. (The students are strongly advised to prepare for this test not only by using ProtoThinker but also by working through the relevant sections of GRE study aid books.) To obtain a passing score on the proficiency exam, a student must have a total score of 25 points, the sum of the historical average of both tests. The students who pass the proficiency exam receive academic credit for PHIL 106.

After the students were introduced to the basic logic and reasoning rules in the first two weeks, they were given a version of the Argument Evaluation Test as a pretest, and averaged 7.6 correct out of 20. The posttest average was 13.5 correct $\left(75^{\text {th }}\right.$ percentile). The California test was administered as a posttest, and the class averaged 17.4 out of $34\left(70^{\text {th }}\right.$ percentile $)$. When the course was offered for the first time in the fall semester of 1996, all 16 students in the class passed the proficiency exam; in the fall semester of 1997, 19 out of 24 students passed the exam.

\section{ENGINEERING PROBLEM SOLVING}

The engineering problem solving content of the course is organized around the scientific method of problem solving and engineering design. While being introduced to basic tools and techniques of logic, the students are systematically exposed to the scientific method of problem solving through interactive class meetings and small projects. Important strategies such as problem definition, problem formulation, generation of alternative solutions, and selection and implementation of the best solution are discussed in detail. Numerous examples are used in interactive class sessions. Basic engineering design steps such as recognition of need, definition of the problem, information collection, conceptualization, evaluation, and communication of design are illustrated by small projects that are completed in a single class period. In addition, several problem representation methods such as tables, diagrams, solution procedures, uncertainties, constraints, and economic aspects of engineering decisions are covered.

The critical thinking content of the course is linked to the problem solving content by integrating the reasoning skills learned earlier into problem-solving steps. The most obvious benefits are observed in the problem-analysis and problem-definition processes. The skills acquired during argument evaluation practices helped the students reason more effectively when trying to identify the real problem rather than the perceived problem in a given situation. The reasoning skills also enhanced their technical report writing skills. When students were asked to recall some of the categorical and propositional argument structures that they dealt with earlier, reports became more precise and the design concepts were more effectively expressed. Certain key words learned in argument evaluation were used appropriately to give precise meanings to sentences. 
Although it is difficult to assess, we think that the reasoning skills also helped students organize their thoughts more effectively and evaluate situations more accurately during the problemsolving processes.

Several software modules developed at the University of Michigan on Strategies for Creative Problem Solving are used in class meetings to communicate important concepts such as problem definition, situation analysis, and problem and decision analysis. Sets of homework assignments are given on each module.

Early in the semester a guest faculty member from the Department of English Language and Literature is invited to introduce basic principles of technical report writing. Students are given comparative examples on how to write concisely, using active voice, organizing with headings and subheadings, revising, and editing. The students are required to submit a technical report on each of their projects. The technical reports are returned to the students with a set of suggested changes. After making the changes, the students turn in revised versions of the reports. The improvements are significant. This method provides the students with an effective opportunity to develop good writing skills through revisions based on corrections to their previous work.

During the first week of the semester, the students play the name game adapted from Professor Raymond Landis of California State University at Los Angeles. They work in randomly formed groups and are required to remember the names of the other group members. Group membership is changed at each class meeting. The name game has proven to be very useful in fostering bonding among the students. For many of the students this peer bonding is important for their future college life. They identify with other engineering freshmen and form friendships that provide a sense of belonging. Without this opportunity they may fail to obtain the informal academic support they need from their peers.

\section{Projects}

Since the students do not have the technical and analytical skills required to solve the assigned problems scientifically, the small projects are carefully designed to provide opportunities to practice the main stages of problem solving and engineering design methods. The students enrolled in the course are declared engineering majors from four engineering disciplines. The projects are selected in different areas of engineering to provide exposure to four engineering programs: electrical, mechanical, civil, and industrial.

The objective of the first project is to design a device that will catch an egg dropped three stories high without breaking it. This project has several restrictions in terms of the weight and dimensions of the tool, in addition to budgetary constraints. A later project involves the design of a car with a self-contained mechanism for stopping. The car, released from a three-foot ramp, makes a jump at the end of the ramp onto a landing platform and must stop before crashing into a wall three feet away. Other projects are very similar, and some are selected from the $1995 \mathrm{NSF}$ workshop on engineering design projects list.

The larger projects are modified and simplified versions of ASME yearly student design competition projects. The students in the 1996 class worked on a project that involved the 
automatic transportation of a Ping-Pong ball from the top of one box to the inside of another placed a specified distance away. Students were limited to using a single AA battery and a simple DC motor as an electromechanical source. The problem had a set of dimensional constraints for the unassembled design and time constraints for assembly and transport. The design teams were ranked with respect to transport distance and time. The senior mechanical engineering class was invited to the term project demonstrations. After the demonstrations, two of the designs provided ideas for the senior class teams for their own projects. This resulted in two freshman students being invited to join the senior competition teams. In 1997 the term project involved automatically sorting two widgets (one with an off-centered hole and one without a hole) deposited into the system in random order and position, using a single AA battery and a DC motor as a power source.

The project teams are formed randomly and changed for each project, thereby fostering development of interpersonal skills and competence in dealing with diverse personalities and decision-making styles. At the beginning of the semester the students are given guidelines on how to conduct team meetings, keep a logbook, prepare an agenda, etc. In addition to submitting technical reports, students make oral presentations and demonstrations of the projects. Members of each team take turns presenting the various parts of the project. Before the first presentation, guidelines are provided on effective oral presentations and use of visual aids. An outline for the technical reports included the following sections:

Problem Statement

Assumptions and Constraints

Relevant Information and Knowledge

Alternative Solutions Considered

Best Solution Selected

An Engineering drawing of the Design

List of Materials

Material Costs

Assembly and Operating Instructions

Experimentation and Verification of the Final results

\section{TEXT MATERIALS}

Although the course does not utilize a specific textbook, class material for the critical thinking section is prepared from a textbook used for PHIL 106, and reasoning rules discussed in the class are condensed into a short handout. The problem solving class meetings are loosely structured and, depending on the agenda, may involve short (15-20 minute) lectures in preparation for interactive sessions on specific topics. The students are repeatedly given small problems and instructed to discuss and work on them with team members or other classmates. Some class meetings focus on basic tools and techniques for systematic analysis and structured thinking, while others center on discussions of basic engineering concepts such as measurement systems, forces, energy, etc. Ideas for class material are gathered from the following sources:

Patterns of Problem Solving by Rubinstein and Firstenberg ${ }^{7}$ 
Strategies for Creative Problem Solving by Fogler and LeBlanc ${ }^{3}$

How to Model It: Problem Solving for Computer Age by Starfield, Smith, and Bleloch ${ }^{8}$

Creative Problem Solving by Lumsdaine and Lumsdaine ${ }^{5}$

An Introduction to Engineering by Onwubiko ${ }^{6}$

Studying Engineering by Landis ${ }^{4}$

\section{COURSE EVALUATIONS}

The School of Engineering has standard multiple-choice course evaluation forms that are given to students at the end of each semester. Owing to the special nature of this course, the forms were modified slightly to aid in evaluating the impact of the ProtoThinker software on the proficiency exam success rate, and to obtain suggestions on ways to improve the course content and format. The first offerings of the course received encouraging feedback from the students. Several students remarked that this course was an oasis during their first semester, a place where they could become involved with engineering topics and concepts. (All the other courses the students take during the first semester are basic science and general education courses, to which they may not strongly relate.) The majority of the students thought that the course was stimulating and made them want to learn more. The material covered in the class was judged relevant and useful. The projects were the favorite aspects of the course. The majority of the students suggested inclusion of more projects as the main way to improve the course, while a significant number suggested inviting guest speakers from industry. A large majority of the students considered ProtoThinker a very useful tool for improving their reasoning skills. The most popular module of ProtoThinker was the GameMaster Module, which enabled the students to evaluate arguments interactively.

\section{CONCLUSIONS AND FUTURE DIRECTIONS}

The course is presently offered on an optional basis to a relatively small number of students who show particular interest in the area. After the first experimental offering, the course became an established course in the engineering curriculum. The long-term objective is to make the course attractive to all engineering freshmen. With the success of the first experiment, there is considerable interest in and support for the course in the School of Engineering. The course still has ample room for improvement in terms of content and format. The objective of the course was to show the students how structured thinking can help them solve complex problems, rather than to provide introductory lectures on fundamental engineering topics. The most important skills students acquire in this course center on systematic methods of finding and evaluating solutions based on sound reasoning. The students learn to ask the right questions and to use relevant information effectively. In addition, this course helps students see the link between science and engineering. This is a very important insight for most freshman engineering students, who typically have only vague ideas about how science relates to engineering, and how the content of their physics, mathematics, and chemistry classes bears upon even the simplest engineering problems. This is accomplished by pointing out the relevant theory on each project they work on. Even though they are not expected to perform a scientific analysis of the given problems, they are encouraged to use their knowledge of science to make predictions and/or investigations about given situations. 
Once the course is well established, we are planning to offer it to all undeclared freshman students in the university. Many freshmen, even those interested in science, are not well informed about engineering, and this course or a modified version of it could provide a suitable opportunity for them to learn what engineering is all about. This would be apt to have a beneficial impact on long term engineering enrollments at SIUE, which has a significant number of undeclared first year students.

Another activity planned for the future is to improve the assessment of the course by tracking the future academic performance of the students enrolled in the course in comparison to other engineering students who were not enrolled. This will give us the necessary data to evaluate the effectiveness of the course with respect to students' professional development.

In summary, although this course is more demanding on faculty than typical engineering courses in terms of development time and interaction with students, we found that interactive learning is rewarding both for the students and the faculty, and helps both parties in numerous ways.

\section{REFERENCES}

[1] Barker, J. A. (1998). ProtoThinker: A Model of the Mind. Belmont, CA, Wadsworth Publishing Company.

[2] Facione, P. (1990). The California Critical Thinking Skills Test: College Level. Millbrae, CA, The California Academic Press.

[3] Fogler, H. S., S. LeBlanc. (1995). Strategies for Creative Problem Solving. Englewood Cliffs, NJ, Prentice Hall.

[4] Landis, R. B. (1994). Studying Engineering. Burbank, CA, Discovery Press.

[5] Lumsdaine, E., M. Lumsdaine. (1995). Creative Problem Solving. New York, NY, McGraw-Hill.

[6] Onwubiko, C. (1997). An Introduction to Engineering. Mission, KS, Schroff Development Corporation.

[7] Rubinstein, M.F., I. Firstenberg. (1995). Patterns of Problem Solving. Englewood Cliffs, NJ, Prentice Hall.

[8] Starfield, A.M., K. Smith, A. Bleloch. (1994). How to Model It: Problem Solving for the Computer Age. Edina, MN, Burgess Publishing.

\section{S. CEM KARACAL}

Associate Professor of Industrial Engineering. He received his BS in Industrial Engineering from METU, Ankara, Turkey and MS and Ph.D. in Industrial Engineering from Oklahoma State University in 1986 and 1991 , respectively. His research interests are in Object Oriented simulation methodologies and wafer fabrication. He is actively involved with freshman engineering class and engineering honor societies at SIUE.

\section{JOHN BARKER}

Professor of Philosophy. Ph.D. in Philosophy, Tulane University, 1967. He specializes in logic, cognitive science, philosophy of mind, epistemology, and philosophy of language. In recent years, he has focused on creating software for research and instructional uses in philosophy and cognitive science, and on developing an Internet-based research and curriculum project in cognitive science.

\section{JACOB VAN ROEKEL}

Program Director and Associate Professor of Industrial Engineering. Served as a practicing industrial/management engineer for 16 of 24 years in the United States Air Force where he developed and led numerous management consultant and human resource standard studies. Since joining academia in 1984, he has pursued interests in computer-integrated manufacturing, minority education, and retention. 